\title{
Effect of Antibiotics on Polymorphonuclear Leukocyte Functions and Myeloperoxidase Activity, Glutathione and Malondialdehyde Levels in Allergic Asthma
}

\author{
PERVIN RAYAMAN ${ }^{1 *}$, ERKAN RAYAMAN ${ }^{1}$, ADİLE ÇEVİKBAŞ $^{1}$, REFIK DEMIRTUNÇ $^{2}$, \\ AHMET ÖZER ŞEHİRLİ ${ }^{3}$, ŞEYDA GÜL ALAGÖZ ${ }^{4}$ and ÜMRAN SOYOĞUL GÜRER ${ }^{1}$ \\ ${ }^{1}$ Marmara University, Faculty of Pharmacy, Department of Pharmaceutical Microbiology, Haydarpaşa-İstanbul, Turkey \\ ${ }^{2}$ Haydarpaşa Numune Training and Research Hospital, Department of Internal Medicine, İstanbul, Turkey \\ ${ }^{3}$ Marmara University, Faculty of Pharmacy, Department of Pharmacology, Haydarpaşa-İstanbul, Turkey \\ ${ }^{4}$ Haydarpaşa Numune Training and Research Hospital, Department of Pneumonology, İstanbul, Turkey
}

Submitted 31 March 2014, revised 3 November 2014, accepted 13 November 2014

\begin{abstract}
We investigated the effect of ciprofloxacin, rifampicine and doxycycline on myeloperoxidase (MPO) activity, glutathione (GSH) and malondialdehyde (MDA) levels in allergic asthma patients and healthy volunteers. Polymorphonuclear leukocytes(PMNs) were isolated with ficoll-hypaque gradient centrifugation method. MPO activity was assayed with modified o-dianisidine, GSH by Ellman's and MDA levels by Beuge's method. PMN functions and MDA levels of patients significantly decreased when compared with healthy volunteers. Ciprofloxacin significantly increased PMN functions, MPO activity and MDA levels of both groups. We have demonstrated that ciprofloxacin has beneficial effects on MPO activity and PMN functions in allergic asthma patients and healthy volunteers.
\end{abstract}

Ke y word s: allergic asthma, antibiotics, intracellular killing activity, myeloperoxidase, phagocytosis

It is known that neutrophils take place during the allergic process and asthma. Oxidative stress takes place in the pathogenesis of inflammatory diseases such as allergic asthma and rhinitis (Kämpe et al., 2011; Öztop et al., 2002).

The deterioration of PMN's intracellular killing activity could cause the intracellular microorganisms to become potential pathogens in the phagocytic cells. Işık et al. (2010) have stated that PMN's intracellular killing activity of patients with allergic rhinitis was insignificantly low when compared to that before immunotherapy $(\mathrm{p}=0.05)$. Also, Gürer et al. (2005) have demonstrated that PMN's intracellular killing activity of patients with seasonal allergic rhinitis before allergen-specific short-term immunotherapy significantly decreased $(\mathrm{p}=0.252)$.

Today it is known that most important PMN defects are leukocyte adhesion insufficiency and myeloperoxidase deficiency. The relationship between PMN's MPO activity and PMN's intracellular killing activity of patients whose intracellular killing activity was found to be low has not been investigated. Also, the cause of oxidative stress in these patients has not been exactly determined. Glutathione (GSH) is a vital antioxidant in the non-enzymatic antioxidant defence system and scavenges free radicals directly (Shurtz-Swirski et al., 2001; Beier et al., 2004).

As an indicator of lipid peroxidation, malondialdehyde (MDA) is made up by free radicals during tissue damage and used in the measurement of oxidative stress (Okur et al., 2006).

We aimed to find out the relationship between PMN functions (phagocytosis and intracellular killing activity) of allergic asthma patients and MPO activity, GSH and MDA levels in our study. The antimicrobial drugs used in the treatment of the infection seen in these patients could negatively affect or increase the enzyme levels. That is why the aim of our study is to find out the effect of ciprofloxacin $(2.5 \mu \mathrm{g} / \mathrm{ml})$, rifampicine $(7 \mu \mathrm{g} / \mathrm{ml})$ and doxycycline $(2.5 \mu \mathrm{g} / \mathrm{ml})$ on PMN functions and MPO activity and GSH and MDA levels of patients with allergic asthma and healthy volunteers in vitro.

In our study 13 allergic asthma patients (1 male and 12 females, mean age 28.85) and healthy volunteers used as the control group consisted of 13 healthy volunteers ( 3 male and 10 females, mean age 39.69).

* Corresponding author: P. Rayaman, Department of Pharmaceutical Microbiology, Faculty of Pharmacy, Marmara University, Haydarpasa, Istanbul, Turkey; e-mail: pgocer2000@yahoo.com 
This study protocol was approved by the Marmara University, Ethics Committee. We used a modified neutrophil function evaluation method of Alexander et al. (1968) to detect PMN functions. The PMN's of patients and healthy volunteers was isolated by using Ficoll-Hypaque method. Viability of PMNs was tested by the trypan blue exclusion method (Alexander et al., 1968; Barbior and Cohen, 1981).

A clinical strain of Candida albicans was used to determine the PMN's phagocytic and intracellular killing activity. C. albicans was opsonizated with sterile human serum $(1: 4)$ at $37^{\circ} \mathrm{C}$ for 30 minutes. Dead yeast cells were assessed by $0.01 \%$ methylene blue stain (1:1). The phagocytic activity was determined by the percentage of PMNs that had phagocytosed yeast cells. Intracellular killing activity was assayed by the percentage of PMNs that included dead yeast cells. (Richardson et al., 1992; Gürer et al., 2006).

The PMN suspension stored was in order to measure PMN's MPO activity, GSH and MDA levels (Kurutas et al., 2005). MPO activity was determined by a modification of the o-dianisidine method. The protein content of the homogenate was measured by Spectronic-UV 120 spectrophotometer using Lowry's method (Lowry et al., 1951; Kurutas et al., 2005).

The MDA levels were assayed for the products of lipid peroxidation by monitoring thiobarbituric acid reactive substance formation as previously described (Beuge and Aust, 1978). GSH levels were measured by modified Ellman procedure (Beutler, 1975).
The in vitro effect of ciprofloxacin $(2.5 \mu \mathrm{g} / \mathrm{ml})$, rifampicine $(7 \mu \mathrm{g} / \mathrm{ml})$ and doxycycline $(2.5 \mu \mathrm{g} / \mathrm{ml})$ on PMN functions and MPO activity, GSH and MDA levels at the therapeutic serum concentration was investigated.

The results were expressed by means of \pm SD (Standart Deviation). Statistical analyses were performed using Mann Whitney U and Wilcoxon Signed Ranks tests. $\mathrm{P}$ values less than or equal to 0.05 were considered to be statistically significant.

PMN's MDA levels of patients with allergic asthma significantly decreased when compared to healthy volunteers $(\mathrm{p}<0.001$, Table I). The PMN's phagocytic $(\mathrm{p}<0.01)$ and intracellular killing activity $(\mathrm{p}<0.001)$ of patients with allergic asthma significantly decreased when compared to healthy volunteers (Table I).

As it is seen from Table II ciprofloxacin significantly increased PMN's phagocytic $(\mathrm{p}<0.01)$ and intracellular killing activity $(\mathrm{p}<0.01)$ of healthy volunteers and patients with allergic asthma when compared to drugfree controls. Rifampicine and doxycycline $(\mathrm{p}<0.05)$ have significantly decreased PMN's phagocytic $(p<0.05)$ and intracellular killing activity $(\mathrm{p}<0.05)$ of healthy volunteers when compared to drug-free controls (Table II).

As it is seen on Table III ciprofloxacin significantly increased PMN's MPO activity $(\mathrm{p}<0.01)$ and MDA levels of patients with allergic asthma $(\mathrm{p}<0.01)$ and healthy volunteers $(p<0.01)$ when compared to drugfree controls. However, while ciprofloxacin has significantly decreased PMN's GSH levels of patients with allergic asthma $(p<0.01)$, it has significantly increased

Table I

PMN Functions (Phagocytic and Intracellular Killing Activity), PMN's MPO activity, GSH and MDA Levels of Healthy Volunteers $(\mathrm{n}=13)$ and Patients $(\mathrm{n}=13)$ with Allergic Asthma

\begin{tabular}{|l|c|c|c|c|c|}
\hline \multicolumn{1}{|c|}{ Group } & PA (\%) & IKA(\%) & $\begin{array}{c}\text { MPO } \\
(\mathrm{U} / \mathrm{mg} \text { protein })\end{array}$ & $\begin{array}{c}\text { GSH } \\
(\mu \mathrm{mol} / \mathrm{mg} \text { protein })\end{array}$ & $\begin{array}{c}\text { MDA } \\
(\mathrm{nmol} / \mathrm{mg} \text { protein })\end{array}$ \\
\hline A. asthma & $40.38 \pm 1.34^{*}$ & $1.54 \pm 0.24^{* *}$ & $237.03 \pm 17$ & $1.93 \pm 0.03$ & $1.92 \pm 0.29^{* *}$ \\
\hline Healthy volunteers & $48.31 \pm 5.27$ & $6.54 \pm 1.39$ & $275.96 \pm 33$ & $1.94 \pm 0.07$ & $2.22 \pm 0.50$ \\
\hline
\end{tabular}

${ }^{*} \mathrm{p}<0.01,{ }^{* *} \mathrm{p}<0.001$. Statistics were done by using Mann Whitney $\mathrm{U}$ test and the data shown is by means of $\pm \mathrm{SD}$.

PA: Phagocytic Activity, IKA: Intracellular Killing Activity, MPO: Myeloperoxidase GSH: Glutathione and MDA: Malondialdehyde

Table II

Comparison of the Effect of Antibiotics on PMN Functions (Phagocytic and Intracellular Killing Activity of Patients with AA(n=13) and Healthy Volunteers $(\mathrm{n}=13)$ with Drug-Free Controls

\begin{tabular}{|c|c|c|c|c|c|c|}
\hline \multirow{2}{*}{ Group } & \multicolumn{2}{|c|}{ Ciprofloxacin $(2.5 \mu \mathrm{g} / \mathrm{ml})$} & \multicolumn{2}{|c|}{ Rifampicine $(7 \mu \mathrm{g} / \mathrm{ml})$} & \multicolumn{2}{|c|}{ Doxycycline $(2.5 \mu \mathrm{g} / \mathrm{ml})$} \\
\hline & PA (\%) & IKA (\%) & PA (\%) & IKA (\%) & PA (\%) & IKA (\%) \\
\hline Control & $48.31 \pm 5.27$ & $6.54 \pm 1.39$ & $48.31 \pm 5.27$ & $6.54 \pm 1.39$ & $48.31 \pm 5.27$ & $6.54 \pm 1.39$ \\
\hline Healthy volunteers & $63.54 \pm 1.89^{*}$ & $9.92 \pm 0.35^{\star}$ & $39.08 \pm 2.39^{\star *}$ & $5.62 \pm 0.35^{\star *}$ & $38.15 \pm 1.82^{\star *}$ & $5.69 \pm 1.62^{\star *}$ \\
\hline Control & $40.38 \pm 1.34$ & $1.54 \pm 0.24$ & $40.38 \pm 1.34$ & $1.54 \pm 0.24$ & $40.38 \pm 1.34$ & $1.54 \pm 0.24$ \\
\hline A. asthma & $54.85 \pm 1.09^{*}$ & $4.39 \pm 0.33^{*}$ & $38.69 \pm 1.62$ & $1.46 \pm 0.33$ & $38.69 \pm 1.62$ & $1.46 \pm 0.33$ \\
\hline
\end{tabular}

${ }^{*} \mathrm{p}<0.01,{ }^{* *} \mathrm{p}<0.05$. Statistics were done by using Wilcoxon Signed Ranks test and the data shown is by means of \pm SD.

PA: Phagocytic Activity, IKA: Intracellular Killing Activity 
Table III

Comparison of the Effect of Antibiotics on PMN's MPO activity, GSH and MDA Levels of Patients with AA ( $\mathrm{n}=13$ ) and Healthy Volunteers $(\mathrm{n}=13)$ with Drug-Free Controls

\begin{tabular}{|c|l|c|c|c|c|}
\hline \multicolumn{2}{|c|}{ Group } & Control (drug-free) & Ciprofloxacin $(2.5 \mu \mathrm{g} / \mathrm{ml})$ & Rifampicine $(7 \mu \mathrm{g} / \mathrm{ml})$ & Doxycycline $(2.5 \mu \mathrm{g} / \mathrm{ml})$ \\
\hline \multirow{2}{*}{ MPO } & A. asthma & $237.03 \pm 17$ & $365.17 \pm 17^{\star}$ & $213.40 \pm 17$ & $224.10 \pm 16$ \\
\cline { 2 - 6 } & Healthy & $275.96 \pm 33$ & $391.58 \pm 30^{*}$ & $272.94 \pm 30$ & $284.33 \pm 27$ \\
\hline \multirow{2}{*}{ GSH } & A. asthma & $1.93 \pm 0.03$ & $1.24 \pm 0.12^{\star}$ & $1.88 \pm 0.02$ & $1.87 \pm 0.03$ \\
\cline { 2 - 6 } & Healthy & $1.94 \pm 0.07$ & $2.19 \pm 0.13^{\star}$ & $1.87 \pm 0.11$ & $1.81 \pm 0.12$ \\
\hline \multirow{2}{*}{ MDA } & A. asthma & $1.92 \pm 0.29$ & $2.70 \pm 0.79^{*}$ & $1.85 \pm 0.48$ & $1.82 \pm 0.31^{* *}$ \\
\cline { 2 - 6 } & Healthy & $2.22 \pm 0.50$ & $2.68 \pm 0.40^{*}$ & $2.28 \pm 0.24^{*}$ & $2.18 \pm 0.39$ \\
\hline
\end{tabular}

${ }^{*} \mathrm{p}<0.01,{ }^{* *} \mathrm{p}<0.05$. Statistics were done by using Wilcoxon Signed Ranks test and the data shown is by means of \pm SD.MPO: Myeloperoxidase, GSH: Gluthathione, MDA: Malondialdehyde

PMN's GSH levels of healthy volunteers $(\mathrm{p}<0.01)$ when compared to drug-free controls. While rifampicine has significantly increased PMN's MDA levels of healthy volunteers $(p<0.01)$, doxycycline has significantly decreased PMN's MDA levels of patients with allergic asthma ( $\mathrm{p}$ 0.05) when compared to drug-free controls.

Patients with allergic asthma are very sensitive against the microorganisms which cause infections. Since the PMN's phagocytic and intracellular killing activity of patients with allergic asthma significantly decreased when compared to healthy volunteers, it must be considered that it is important to identify the antibiotics and the other drugs which are used in the treatment of this diseases.

Beside their successful therapeutic effects, many frequently used drugs could affect the immune system positively or negatively (Badur, 1991; Gemmell, 1993).

Ciprofloxacin significantly increased the PMN's MDA level in healthy volunteers and patients with allergic asthma in our study. Possibly the excessively increased MPO activity by ciprofloxacin has increased the lipid peroxidation in the cell. This might lead to the increase of MDA level. In our opinion there is necessity for much more clinical and in vitro investigations.

Szczepaniak et al. (2003) showed that there is no significant difference between the MPO release from peripheral blood neutrophils of patients with allergic respiratory tract disease and healthy volunteers. In their study Boner et al. (1993) has found that while total IgE levels of 12 asthmatic children increased after exposure to allergen-rich environments, their serum MPO levels did not change.

In our study ciprofloxacin has significantly increased the PMN's MPO activity in patients with allergic asthma $(\mathrm{p}<0.01)$. Related with the increase in the MPO activity, there has been an increase in both PMN functions of these patients (Table II, $\mathrm{p}<0.01$ ).

The PMN's GSH levels of patients with allergic asthma significantly have decreased $(p<0.01)$ after ciprofloxacin, while their MDA have levels significantly increased $(\mathrm{p}<0.01)$.
Öztop etal. (2002) have stated that the serum GSH-Px levels of patients with mild and moderate asthma were significantly lower than healthy volunteers $(\mathrm{p}<0.05)$, but their MDA levels were significantly higher $(\mathrm{p}<0.05)$.

There is no investigation showing the interaction between PMN functions, MPO activity, GSH and MDA levels in patients with allergic asthma. Gürer et al. (2006) have shown that ciprofloxacin signficantly increased the PMN's phagocytic activity of elderly patients $(\mathrm{p}=0.002)$ before zinc supplementation and significantly increased both PMN functions of elderly patients $(\mathrm{p}=0.002)$ after zinc supplementation $15 \mathrm{mg}$ /day for 1 month. The same antibiotic significantly increased both PMN functions of healthy young volunteers $(\mathrm{p}=0.005$ and $\mathrm{p}<0.05$, respectively) before and after zinc supplementation when compared to control values (drug-free). However, the same investigators have staded that rifampicine significantly decreased the PMN's phagocytic activity of elderly patients $(p<0.05)$ when compared to drug-free values before zinc supplementation.

Also, Daşdelen et al. (1999) have reported that rifampicine $(7 \mu \mathrm{g} / \mathrm{ml})$ and doxycycline $(2.5 \mu \mathrm{g} / \mathrm{ml})$ have significantly decreased PMN's phagocytic $(\mathrm{p}<0.05)$ and intracellular killing activity $(\mathrm{p}<0.01)$ of healthy volunteers when compared to drug-free values.

The results of our study are in accordance with the results of Gürer et al. (2006) and Daşdelen et al. (1999). Additionally, the increase of PMN's MDA levels, by rifampicine in healthy volunteers might be related with the increase of PMN's phagocytic and intracellular killing activity.

In conclusion, ciprofloxacin has stimulated cellular immunity by increasing PMN functions and MPO activity in healthy volunteers and patients with allergic asthma. Beside these beneficial effects there might be cellular damage when MDA increases. We believe that the addition of various antioxidants to the treatment of these patients and proving our in vitro results by clinical investigations might bring more successful results to the therapy of allergic asthma. 


\section{Acknowledgements}

The authors are thankful to all volunteers and the Scientific Research Commission at Marmara University, which supported this study by Project SAG-DKR-060907-0184(2010).

\section{Literature}

Alexander J.W., D.B. Windhorst and R.A. Good. 1968. Improved tests for the evaluation of neutrophil function in human disease. J. Lab. Clin. Med. 72(1): 36-48.

Badur S. 1991. Deleterious effects of antibiotics on immune system (in Turkish ). Klimik Derg. 4(3): 105-108.

Barbior B.M. and H.J. Cohen. 1981. Measurement of Neutrophil Function: Phagocytosis, Degranulation, the Respiratory Burst and Bacterial Killing. $1^{\text {st }}$ ed., pp. 1-38. In: Cline M.J.(Ed). Methods in Hematology, Leukocyte Function Churchill Livingstone, New York. Beier J., K.M. Beeh and D. Semmler. 2004. Increased concentrations of glutathione in induced sputum of patients with mild or moderate allergic asthma. Ann. Allergy. Asthma. Immunol. 92(4): 459-463. Beuge J.A. and S.D. Aust. 1978. Microsomal lipid peroxidation, Meth. Enzymol. 52: 302-311.

Beutler E. 1975. Glutathione in Red Blood Cell Metabolism. pp. 112-114. In: A Manual of Biochemical Methods. Grune\&Stratton, New York. Boner A.L., D.G. Peroni and G.L. Piacentini. 1993. Influence of allergen avoidance at high altitude on serum markers of eosinophil activation in children with allergic asthma. Clin. Exp. Allergy. 23(12): 1021-1026.

Daşdelen N., Ü.S. Gürer and A. Çevikbaş. 1999. In vitro investigation of antibiotic combinations that have inhibitory and immunomodulatory effects on human PMN function (in Turkish). Türk Mikrob. Cem. Derg. 29: 17-22.

Gemmell C.G. 1993. Antibiotics and neutrophil function-potential immunomodulating activities. J. Antimicrob. Chemother. Feb; 31 Suppl. B: 23-33.

Gürer Ü.S., S. Büyüköztürk and Ş. Palandüz. 2005. The effects of allergen-specific immunotherapy on polymorphonuclear leukocyte functions in patients with seasonal allergic rhinits. Int. Immunopharmacol. 5: 661-666.

Gürer Ü.S., P. Göçer and E. Erçağ. 2006. Effects of some antibiotics on polymorphonuclear leukocyte functions of elderly patients in vitro before and after zinc suplementation. Int. Immunopharmacol. 6: 808-816.

Işık H., A. Cevikbaş and U.S. Gürer. 2010.Potential adjuvant effects of Nigella sativa seeds to improve specific immunotherapy in allergic rhinitis patients. Med. Princ. Pract. 19(3): 206-11.

Kämpe M., I. Stolt, M. Lampinen and M. Carlson. 2011. Patients with allergic rhinitis and allergic asthma share the same pattern of eosinophil and neutrophil degranulation after allergen challenge. Clin. Mol. Allergy. 9(3):1-10.

Kurutas E.B., A. Cetinkaya and E. Bulbuloglu. 2005. Effects of antioxidant therapy on leukocyte myeloperoxidase and $\mathrm{Cu} / \mathrm{Zn}$ Superoxide dismutase and plasma malondialdehyde levels in experimental colitis. Mediators. Inflamm. 14(6): 390-394.

Lowry O.H., N.J. Rosebrough and A. Farr. 1951.Protein measurement with the Folin phenol reagent. J. Biol. Chem. 193(1): 265-275. Okur E., F. Inanc and M.A. Kilic. 2006. Malondialdehyde level and adenosine deaminase activity in nasal polyps. Otolaryngol. Head. Neck. Surg. 134(1):37-40.

Öztop A., A. Demir and N. Saydam. 2002 .Relationship between serum gluthatione peroxidase, superoxide dysmutase, malonyldialdehyde levels and severety in allergic asthma (in Turkish). Sol. Hastalikları 13: 239-245.

Richardson M.D., G. Scott and G.S. Shankland. 1992. Effect of ciloftragin on phagocytosis and intracellular killing of Candida albicans by human neutrophilis. Eur. J. Clin. Microbiol. Infect. Dis. 11(1): 22-26.

Shurtz-Swirski R., S. Sela, A.T. Herskovits, S.M. Shasha, G. Shapiro, L. Nasser and B. Kristal. 2001. Involvement of peripheral polymorphonuclear leukocytes in oxidative stress and inflammation in type 2 diabetic patients. Diabetes Care 24(1): 104-110.

Szczepaniak W., W. Medrala and A. Wolańczyk-Medrala. 2003. Neutrophil myeloperoxidase release by selected extrinsic allergens. Pol. Merkur. Lekarski 14(79): 31-35. 